\title{
Right Ventricular Outflow Tract Reconstruction in Patients With Persistent Truncus Arteriosus A 15-Year Experience in a Single Japanese Center
}

\author{
Osami Honjo, MD; Yasuhiro Kotani, MD*; Teiji Akagi, MD*; Satoru Osaki, MD*; \\ Masaaki Kawada, MD*; Kozo Ishino, MD*; Shunji Sano, MD*
}

\begin{abstract}
Background The present study analyzes a 15-year experience of repairing persistent truncus arteriosus (PTA) with a consistent policy of right ventricular outflow tract (RVOT) reconstruction (ie, direct anastomosis).

Methods and Results This retrospective study included 13 consecutive patients with PTA (8 type I PTA, 5 type II) who underwent primary repair from September 1992 to December 2006. Median age and body weight at surgery were 21 days and $2.9 \mathrm{~kg}$, respectively. All but 1 patient underwent RVOT reconstruction by direct anastomosis with a monocusp patch. There were 2 operative deaths (12\%). No patient had a pulmonary hypertensive crisis. The median duration of ventilation was 5 days. Another patient died from cardiogenic shock resulting from late cardiac tamponade 2 months after surgery. Four patients (40\%) required balloon angioplasty and 5 $(50 \%)$ required re-operation for branch pulmonary artery and/or conduit obstruction during the median followup period of 70 months (44-174 months). Freedom from all re-interventions and re-operation at 5 years was 50\% (95\% confidence limits, 19-81\%) and 60\% (95\% confidence limits, 30-91\%), respectively.

Conclusions Reasonable early and long-term results can be achieved with direct anastomosis. Further reduction of the re-intervention rate could be attained by refining the surgical techniques and catheter intervention strategies. (Circ J 2007; 71: 1776-1780)
\end{abstract}

Key Words: Congenital heart disease; Persistent truncus arteriosus; Right ventricular outflow tract reconstruction

$\mathbf{P}$ ersistent truncus arteriosus (PTA), an uncommon congenital heart disease accounting for less than $3 \%$ of all congenital heart diseases, 1 is characterized by a single arterial trunk that arises from the base of both ventricles and sustains systemic, coronary, and pulmonary circulation, as well as the presence of a ventricular septal defect (VSD). Since McGoon et al reported the first successful surgical repair of PTA using an aortic homograft in 1967 , incremental advances in surgical and perioperative management have resulted in a dramatic improvement in the outcome of this entity ${ }^{3-8}$ However, the overall outcome in patients with PTA is till compromised by associated anomalies, such as truncal valve insufficiency ${ }^{9}$ or interrupted aortic arch, ${ }^{10}$ and progressive obstruction of the conduit placed in the right ventricular outflow tract (RVOT) and associated peripheral pulmonary artery (PA) stenosis ${ }^{5-7,11}$

RVOT reconstruction in patients with PTA was initially achieved using a xenograft valved synthetic conduit in the 1980s ${ }^{11}$ and small homografts have become the first choice with the recognition of the advantages of elective neonatal repair of this lesion, especially in North American institutes, 3,4 Nonetheless, controversy still remains over the best method of RVOT reconstruction because of the considera-

(Received April 16, 2007; revised manuscript received June 19, 2007; accepted July 20, 2007)

Division of Cardiovascular Surgery, The Hospital for Sick Children, Toronto, Canada, *Department of Cardiovascular Surgery, Okayama University Graduate School of Medicine and Dentistry, Okayama, Japan

Mailing address: Osami Honjo, MD, Division of Cardiovascular Surgery, The Hospital for Sick Children, Toronto, 555 University Avenue, Toronto, ON, M5G, 1X8 Canada. E-mail: osami.honjo@sickkids.ca bly high rates of re-operation on RVOT conduits, regardless of conduit type, and less availability of small homografts in many countries, including Japan5,6,12 Reconstruction of the RVOT by direct anastomosis between the RVOT and PA has emerged as a viable alternative in PTA repair that does not need homografts and also theoretically preserves the growth potential of the native PA thereby reducing re-operation rates $!^{13-16}$ Given the limited availability of homografts, and the growth potential of the native PA, over the past decade we have consistently reconstructed the RVOT in patients with PTA by means of direct anastomosis. This study was undertaken to analyze our 15-year experience in PTA repair using a consistent policy of RVOT reconstruction.

Table 1 Associated Cardiac Anomalies

\begin{tabular}{ll}
\hline \hline Associated anomalies & $N$ \\
\hline Cardiac anomalies & \\
Truncal valve regurgitation & \\
$\quad$ Mild & 6 \\
$\quad$ Moderate & 1 \\
Severe & 2 \\
Interruption of the aortic arch & 1 \\
Single coronary artery & 1 \\
Unroofed coronary sinus & 1 \\
Multiple ventricular septal defect & 1 \\
Atrial septal defect & 6 \\
Partial anomalous pulmonary venous return & 2 \\
Cortriatrium & 1 \\
Aberrant subclavian artery & 3 \\
Persistent left superior vena cava & 2 \\
\hline
\end{tabular}




\section{Methods}

\section{Patients}

We conducted a retrospective study of 13 consecutive patients with PTA who underwent primary total correction in the neonatal or early infantile period from September 1992 to December 2006 at Okayama University hospital. The Institutional Review Board approved this retrospective study, and patient consent was waived. The age at operation ranged from 7 to 300 days (median, 21 days) and 10 of 13 patients $(77 \%)$ were less than 30 days of age. The body weight ranged from 2.1 to $3.9 \mathrm{~kg}$ (median, $2.9 \mathrm{~kg}$ ) and 3 patients weighed less than $2.5 \mathrm{~kg}$. Eight patients had Collet and Edwards ${ }^{17}$ type I PTA and 5 had type II. Associated cardiovascular anomalies are listed in Table 1. Nine patients had a complete muscular VSD and 3 patients had a perimembranous VSD. The truncal valve was tricuspid in 6 patients and quadracuspid in 7 patients, of whom 2 had severe truncal valve regurgitation. Four patients required mechanical ventilation preoperatively, and 1 of them went into shock requiring cardiopulmonary resuscitation.

\section{Operative Procedures}

The operation was performed through a median sternotomy. Cardiopulmonary bypass (CPB) was commenced with aortic and bicaval cannulations at a flow rate of 150 $180 \mathrm{ml} \cdot \mathrm{min}^{-1} \cdot \mathrm{kg}^{-1}$ and the procedures were performed under moderate or deep hypothermia. Intermittent periods of circulatory arrest were used in 2 patients. Myocardial protection was obtained by intermittent antegrade crystalloid cardioplegia (Modified St Thomas' solution, $20 \mathrm{ml} / \mathrm{kg}$ at initial injection followed by $10 \mathrm{ml} / \mathrm{kg}$ for maintenance), which was given every $20 \mathrm{~min}$. The PA was excised from the ascending aorta, and the truncal valve was inspected to determine morphology and function. In 2 recent patients, the aorta was transected to provide excellent exposure of the orifices of the branch PAs and coronary arteries. The defect in the ascending aorta was then closed either directly or with a Dacron patch. VSD was approached though a right ventricular (RV) vertical incision and was closed with a Dacron patch. Since 2001, modified ultrafiltration has routinely been performed for $10-15 \mathrm{~min}$ at the termination of CPB. The sternum was left open in 6 patients and then closed in the intensive care unit following hemodynamic stability, and was primarily closed in the operation room in 7 patients. Glyceryl trinitrate $\left(6 \mu \mathrm{g} \cdot \mathrm{kg}^{-1} \cdot \mathrm{min}^{-1}\right)$ was routinely given to prevent a pulmonary hypertensive crisis. Nitric oxide was also used for selected patients with considerably high postoperative RV pressure that was refractory to the glyceryl trinitrate infusion.

\section{RVOT Reconstruction}

All but 1 patient underwent RVOT reconstruction by direct anastomosis with an anterior wall augmentation. In 10 patients, the posterior wall of the PA was directly anastomosed to the RVOT according to the technique described by Barbero-Marcial et al, ${ }^{14,15}$ whereas either the left atrial appendage or a homograft patch was interposed to reconstruct the posterior wall of the RVOT in 2 patients with type II PTA. The anterior wall was reconstructed either with a bovine pericardial patch having a monocusp valve $(n=3)$, or with a handmade pericardial patch with a polytetrafluoroethylene (PTFE) monocusp $(n=9)$. The Lecompte maneuver ${ }^{18}$ was performed in recent 2 patients with type II PTA. One patient underwent RVOT reconstruction using a 12-mm

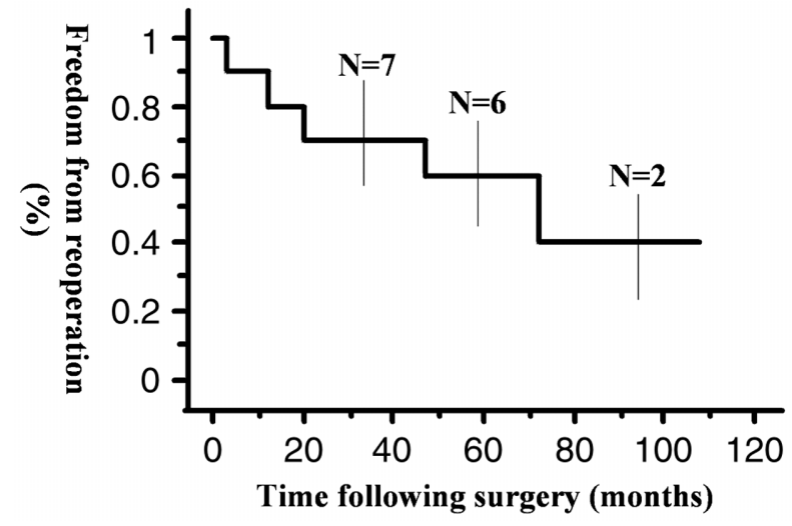

Fig 1. Actuarial freedom from re-operation in 10 patients who underwent primary repair of persistent truncus arteriosus by direct anastomosis.

porcine valved Dacron conduit because the patient a late referral at age 300 days and development of pulmonary vascular disease was highly suspected.

\section{Concomitant Procedures}

Two patients with severe truncal valve regurgitation underwent truncal valve repair. Both had a quadracuspid truncal valve. One of them with a thickened valve with restricted leaflet motion underwent slicing of the thickened leaflet, and the other, who had central regurgitation, underwent leaflet resuspension. One patient with interrupted aortic arch underwent aortic arch reconstruction with isolated cerebral and myocardial perfusion. 19

\section{Follow-up and Re-Intervention}

The patients were followed-up by echocardiography performed every 6 months or less. RV dilatation was estimated by comparing the RV end-diastolic dimension of the patient measured by M-mode with the value of normal population: ${ }^{20}$ mild dilatation, $<124 \%$ of normal value; moderate dilatation, from $125-149 \%$ of normal value; severe dilatation, $>150 \%$ of normal value. RV wall motion was expressed by the examiner as normal, mildly depressed, moderately depressed, or severely depressed. Other parameters included the degree of obstruction of peripheral PAs and/or conduit, conduit insufficiency, and truncal valve stenosis and/or insufficiency.

Re-intervention, either catheter-based intervention or surgery, was indicated if a patient had persistently increased $\mathrm{RV}$ pressure more than two-thirds of systemic pressure caused by RVOT obstruction and/or considerable branch PA stenosis with risk of loss of branch PA flow.

\section{Statistical Analysis}

The medical records, operative reports, and echocardiographic results for all patients were reviewed and follow-up was complete for all patients. The rates of freedom from reoperation and re-intervention were estimated by the Kaplan-Meier method.

\section{Results}

There were 2 operative mortalities (12\%). Both patients underwent operation before 1996 and had associated anomalies: interruption of the aortic arch, and massive truncal valve regurgitation with DiGeorge syndrome, respectively. The former patient died from intracranial hemorrhage on 


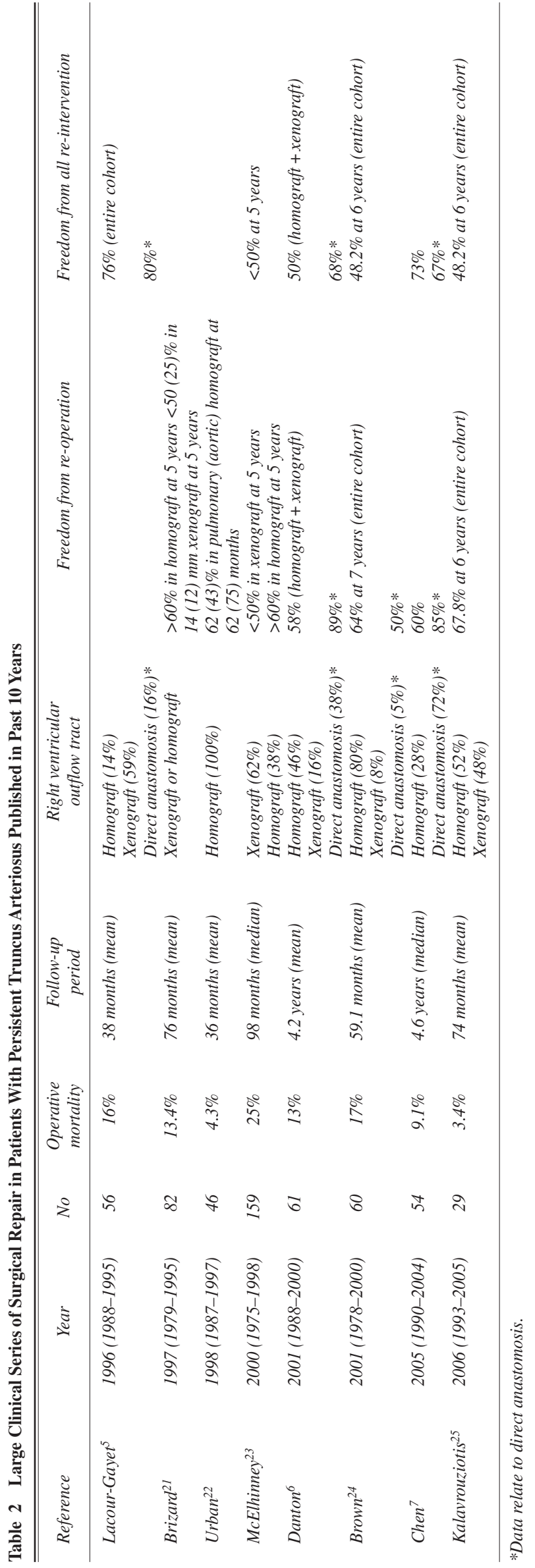

the 8th postoperative day and the latter died of multiorgan failure despite 7 days of extracorporeal membrane oxygenation. No patient had a pulmonary hypertensive crisis. The median duration of mechanical ventilation was 5 days (range, 3-18 days).

\section{Mid-Term and Late Outcomes}

One patient died from cardiogenic shock as a result of late cardiac tamponade 2 months after surgery. The median follow-up period was 70 months (range, 44-174 months). Among 10 long-term survivors, $4(40 \%)$ required balloon angioplasty for the branch PA and/or conduit obstruction, of which 2 patients had bilateral peripheral PA stenosis, 1 patient had diffuse stenosis in the right PA, and 1 patient had a discrete stenosis in the main PA pericardial patch. Five patients $(50 \%)$ required 6 re-operations because of peripheral PA stenosis in 3 patients (bilateral, 2; right, 1), rapidly-developed discrete RVOT obstruction due to hypertrophy of the pericardial patch placed on the anterior wall of the main PA in 1 patient, and conduit stenosis in 1 patient. Doppler estimate of the mean RV/LV pressure ratio in the 5 patients who required re-operation was $0.76 \pm 0.28$, and the degree of tricuspid regurgitation was mild in 4 patients and moderate in 1 patient prior to re-operation. The degree of RV dilatation was mild in 3 patients and moderate in 2 patients. RV wall motion was normal in 4 patients and mildly depressed in 1 patient. There was no re-operation associated with truncal valve regurgitation or stenosis. The procedures included relief of peripheral PA stenosis using either a pericardial or PTFE patch in 4 patients, RVOT re-reconstruction in 3 (pericardial patch with PTFE monocusp in 2 , bovine pericardial patch with a monocusp in 1), and closure of residual VSD in 1. Another re-operation was required in 1 patient 7 years after the first re-operation in whom a porcine biosynthetic valve was inserted in the pulmonary position. The Kaplan-Meier estimate of freedom from all re-interventions, including balloon angioplasty and re-operation, at 5 years was $50 \%$ (95\% confidence limits, 19-81\%) and 60\% (95\% confidence limits, 3091\%), respectively (Fig 1).

\section{Follow-up}

At the latest follow-up, all patients were in New York Heart Association class I, and 5 (50\%) of 10 patients were taking low-dose oral diuretics. On the last echocardiography, mild RV dilatation was detected in 4 patients. There was no evidence of reduced RV wall motion in any of the patients. The mean RV-PA pressure gradient on Doppler study was $24 \mathrm{mmHg}$ (range, $11-37 \mathrm{mmHg})(\mathrm{n}=7)$, and conduit valve regurgitation was mild in 8 patients and moderate in 2 patients. Truncal valve regurgitation was none or trivial in 3 patients and mild in 7 patients, and no truncal valve stenosis was detected. Tricuspid regurgitation was trivial in 4 patients, and mild in 6 patients.

\section{Discussion}

In the present study, we reviewed our 15-year experience of PTA repair, with a special emphasis on RVOT reconstruction, and found that primary repair of this entity with direct anastomosis in the neonatal or early infantile period had reasonable early and long-term outcomes. Given the fact that the only 2 operative mortalities occurred before 1996 and that perioperative management, including CPB strategy and pulmonary vascular resistance lowering thera- 
pies, has dramatically improved over the last decade, a better early outcome would be expected in the next decade. The rate of re-operation was also reasonable and nearly equivalent to that for homografts and was better than that for small-sized xenografts reported in a previous clinical series (Table 2), $3-7,11$ although $50 \%$ of the patients required catheter intervention and re-operation within 2 years either on the RVOT or on the peripheral PAs because of progressive obstruction in which the stenotic lesions were often refractory to catheter intervention. Since the last echocardiographic analysis showed preserved RV wall motion and acceptable truncal and conduit regurgitation or stenosis, progressive obstruction of the RVOT and/or peripheral PAs is definitely the chief factor compromising the long-term outcome in patients with PTA in our series, and therefore the discussion should be focused on how to improve RVOT reconstruction to minimize the risk of re-intervention.

RVOT reconstruction by direct anastomosis, which was first proposed by Reid et $\mathrm{al}^{13}$ and later popularized by Berbero-Marcial et al in the early $1990 \mathrm{~s},{ }^{14,15}$ has been used in several institutes for selected patients ${ }^{5-7}$ (Table 2). Among the large clinical series of patients with PTA reported in the past decade, ${ }^{5,21-25} 4$ institutes have used this technique, but surgical results have been inconsistent among the series. The first large series including direct anastomosis reported by Lacour-Gayet et al in $1996^{5}$ revealed that direct anastomosis was related to high hospital mortality (48.8\%) but was associated with high re-intervention-free rate (Table 2). A larger series reported by Danton et al showed a similar trend in which direct anastomosis was related to high hospital mortality, but had a significantly higher re-operationfree rate6 Most notably, Chen et al recently reported the largest series of direct anastomosis, in which 39 of 54 patients were repaired by direct anastomosis, showing that direct anastomosis reduced the need of re-operation (reoperation rate: homograft, $40 \%$ vs direct anastomosis, $15 \%$ ), while the need for any re-intervention was similar between the 2 groups? A consistent positive finding in the previous clinical series is the reduction in the re-operation rate by the use of direct anastomosis, but the main concerns of this approach include a possible high mortality rate seen in the 2 series, especially when it is used in patients at risk of postoperative pulmonary hypertensive crisis, and a negligible advantage of reducing the all intervention rate.

The most attractive advantage of direct anastomosis is preserving the growth potential of the native PA, thereby theoretically reducing or even avoiding re-operation; $6,7,14,15$ however, little evidence has been shown that the native PA actually 'grows' after this procedure. Fujiwara et al showed that the diameters of the reconstructed main PAs increased from $10-18 \mathrm{~mm}$ to $18-21 \mathrm{~mm}$ at the median follow-up period of 2 years in 4 of 5 cases of various types of congenital heart diseases repaired by direct anastomosis, including 1 patient with PTA; 16 however, none of the large series have detected or evaluated the growth of the reconstructed main PA5-7 We did not evaluate whether the reconstructed main PAs grew over time, but the growth potential, if any, certainly did not contribute to the reduction of the re-intervention rate in this study. The main cause of re-intervention in our series was obstruction of the peripheral PAs, which is one of the most striking disadvantages of direct anastomosis. Extensive mobilization of the branch PAs in order to anastomose directly to the RV produces excessive tension and causes branch PA stenosis. In our series, the magnitude of branch PA stenosis because of excessive tension seems to outweigh the benefit of direct anastomosis (ie, growth potential of the native PA); therefore, avoidance of branch $\mathrm{PA}$ stenosis is the key to reduce the re-operation rate. We recently attempted 2 modifications of the technique to solve this issue. Anterior translocation of the PA was performed in 2 recent patients, which potentially avoided branch PA stenosis, especially of the right PA tht lies behind the large ascending aorta. The other technique was to detach the PA from the ascending aorta with as much aortic tissue as possible, thereby minimizing the tension on the branch PAs when anastomosing to the RV. There has been no re-intervention or re-operation required in 4 recent patients so far and hopefully these technical modifications will lead to a reduction in the re-intervention rate.

Many surgeons preclude the use of direct anastomosis as a primary option in repairing PTA, mainly because of the lack of a competent trileaflet valve in the pulmonary position, which could lead to severe pulmonary regurgitation and acute RV failure? ${ }^{21}$ The lack of competence in the pulmonary valve would be particularly critical if the patient suffers a pulmonary hypertensive crisis in the acute postoperative period. In fact, the high mortality rate in the direct anastomosis group seen in some clinical series is mainly because of pulmonary hypertensive crisis 5,6 However, a critical hypertensive crisis can be managed owing to improvements in the current era in therapies used to lower pulmonary vascular resistance ${ }^{26}$ Danton et al also claimed that a monocusp placed on the anterior hood is likely to function competently, at least during the most critical period, despite the fact that its function might worsen with time, and suggested that this technique could be used in the neonate or younger infant, when the risks of pulmonary hypertension are less? We agree with that because there was no mortality or morbidity related to incompetent monocusp or pulmonary hypertensive crisis in our series. We used the valved xenograft in a selected patient who was at risk of postoperative pulmonary hypertensive crisis. In addition, the monocusps have functioned reasonably well during the follow-up period and only $20 \%$ of the hospital survivors had more than moderate pulmonary regurgitation. In the long-term, however, we may have to consider inserting a competent mechanical or biosynthetic valve in the pulmonary position because long-term follow-up of patients with tetralogy of Fallot shows that longstanding pulmonary regurgitation is strongly related to RV failure, ventricular arrhythmia, and sudden death. 27

One of the reasons for the relatively high re-operation rate in our series was that catheter intervention was often ineffective for relieving branch PA stenosis. Endovascular stents were not inserted in any of the patients in this series because of the lack of availability of flexible stents able to be placed in the branch PAs. Therefore, repeated catheter intervention was avoided because of our premise that surgical relief of the branch PA stenosis would be more effective and durable than balloon angioplasty. Indeed, surgical relief of the branch PA stenosis was quite effective and no re-operation was necessary for recurrent branch PA stenosis. Although endovascular stents placed in the PAs have reduced or delayed re-operation in some series, 728 the efficacy of flexible stents in stenotic branch PAs in patients with PTA is still uncertain because the mechanical obstruction created by compression and/or excessive tension related to direct anastomosis are often refractory to catheter-based interventions. Nonetheless, the availability of small flexible stents in Japan would give us another option for managing 
selected patients who have favorable branch PA anatomy for catheter-based re-intervention.

Unlike North America or European countries, there is little information about the clinical practice for treating patients with PTA in Japan. The annual report of the Japanese Association for Thoracic Surgery in 2004, in which 539 institutes were enrolled, revealed that 17 patients with PTA underwent surgery in the neonatal or early infantile period with a mortality rate of $33 \% 2^{29}$ Some institutes recently reported long-term outcomes of RVOT reconstruction for various types of congenital heart diseases, including PTA, but the surgical results of PTA repair have not specifically been analyzed in those studies ${ }^{30,31}$ Yaku et al reported their surgical experience of 12 patients with PTA, with a mortality rate of $12 \%$, in which either a xenograft or a valved pericardial roll was used to reconstruct the RV-PA continuity32 The present study is probably the largest surgical series of PTA reported from a single Japanese center and reports a surgical strategy that does not use a homograft and its early and long-term outcomes.

\section{Conclusions}

Reasonable early and long-term results have been achieved with a policy of RVOT reconstruction by direct anastomosis in patients with PTA, indicating that our surgical strategy meets the challenge of reconstructing the RVOT when homografts are not available. The re-operation rate of this approach was nearly comparable with that for homografts, but further reduction of the re-operation and/or reintervention rate can be attained by continuing efforts to refine the surgical technique and catheter intervention strategies. Close attention should be paid to main and branch PA stenosis, as well as to RV function, because a monocusp placed in the pulmonary position is inherently incompetent.

\section{References}

1. Kieth JD, Rowe RD, Vlad P. Truncus arteriosus. In: Kieth JD, editor. Heart disease in infancy and childhood, 3th edn. New York: Macmillan; 1978.

2. McGoon DC, Rastelli GC, Ongley PA. An operation for the correction of truncus arteriosus. JAMA 1968; 205: 69-73.

3. Hanley FL, Heinemann MK, Jonas RA, Mayer JE Jr, Cook NR, Wessel DL, et al. Repair of truncus arteriosus in the neonate. J Thorac Cardiovasc Surg 1993; 105: 1047-1056.

4. Bove EL, Lupinetti FM, Pridjian AK, Beekman RH $3^{\text {rd }}$, Callow LB, Snider AR, et al. Results of a policy of primary repair of truncus arteriosus in the neonate. Ann Thorac Surg 1989; 47: 499-506.

5. Lacour-Gayet F, Serraf A, Komiya T, Sousa-Uva M, Bruniaux J, Touchot A, et al. Truncus arteriosus repair: Influence of techniques of right ventricular outflow tract reconstruction. $J$ Thorac Cardiovasc Surg 1996; 111: 849-856.

6. Danton MHD, Barron DJ, Stumper O, Wright JG, De Giovannni, Silove ED, et al. Repair of truncus arteriosus: A considered approach to right ventricular outflow tract reconstruction. Eur J Cardiothorac Surg 2001; 20: 95-104

7. Chen JM, Glickstein JS, Davies RR, Mercando ML, Hellenbrand WE, Mosca RS, et al. The effect of repair technique on postoperative right-sided obstruction in patients with truncus arteriosus. J Thorac Cardiovasc Surg 2005; 129: 559-568.

8. Imamura M, Drummond-Webb JJ, Sarris GE, Mee RB. Improving early and intermediate results of truncus arteriosus repair: A new technique of truncal valve repair. Ann Thorac Surg 1999; 67: 1142-1146.

9. Jahangiri M, Zurakowski D, Mayer JE, del Nido PJ, Jonas RA. Repair of the truncal valve and associated interrupted arch in neonates with truncus arteriosus. J Thorac Cardiovasc Surg 2000; 119: 508514.

10. Konstantinov IE, Karamlou T, Blackstone EH, Mosca RS, Lofland GK, Caldarone CA, et al. Truncus arteriosus associated with interrupted aortic arch in 50 neonates: A Congenital Heart Surgeons
Society study. Ann Thorac Surg 2006; 81: 214-222.

11. Reddy VM, Rajasinghe HA, McElhinney DB, Hanley FL. Performance of right ventricle to pulmonary artery conduits after repair of truncus arteriosus: A comparison of Dacron-housed porcine valves and cryopreserved allografts. Semin Thorac Cardiovasc Surg 1995; 7: $133-138$.

12. Motomura N, Takamoto S, Murakawa T, Yoneda N, Shibusawa S, Maeda K, et al. Short-term result of aortic valve replacement with cryopreserved homograft valve in the University of Tokyo Tissue Bank. Artif Organs 2002; 26: 449-452.

13. Reid KG, Godman MJ, Burns JE. Truncus arteriosus: Successful surgical correction without the used of a valved conduit. Br Heart $J$ 1986; 56: $388-390$.

14. Barbero-Marcial M, Riso A, Atik E, Jatane A. A technique for correction of truncus arteriosus type I and II without extracardiac conduits. J Thorac Cardiovasc Surg 1990; 99: 364-369.

15. Barbero-Marcial M, Tanamati C. Alternative nonvalved techniques for repair of truncus arteriosus: Long-term results. Semin Thorac Cardiovasc Surg Pediatr Card Surg Annu 1999; 2: 121-130.

16. Fujikawara K, Naito Y, Komai H, Noguchi Y, Nishimura Y, Suzuki $\mathrm{H}$, et al. Evaluation of the growth off a new pulmonary trunk after the reconstruction of right ventricular outflow tract without using an extracardiac conduit. J Jpn Assoc Thorac Surg 1998; 46: 432 -439.

17. Collet RW, Edwards JE. Persistent truncus arteriosus: A classification according to anatomic types. Surg Clin North Am 1949; 29: $1245-$ 1270.

18. Lecompte Y, Zannini L, Hazan E, Jarreau MM, Bex JP, Tu TV, et al. Anatomic correction of transposition of the great arteries. J Thorac Cardiovasc Surg 1981; 82: 629-631.

19. Ishino K, Kawada M, Irie H, Kino K, Sano S. Single-stage repair of aortic coarctation with ventricular septal defect using isolated cerebral and myocardial perfusion. Eur J Cardiothorac Surg 2000; 17: 538 542.

20. Kampmann C, Wiethoff CM, Wenzel A, Stolz G, Betancor M, Wippermann CF, et al. Normal values of M mode echocardiographic measurements of more than 2000 healthy infants and children in central Europe. Heart 2000; 83: 667-672.

21. Brizard CP, Cochrane A, Austin C, Nomura F, Karl TR. Management strategy and long-term outcome for truncus arteriosus. Eur $J$ Cardiothorac Surg 1997; 11: 687-695.

22. Urban AE, Sinzobahamvya N, Brecher AM, Wetter J, Malorny S. Truncus arteriosus: Ten-year experience with homograft repair in neonates and infants. Ann Thorac Surg 1998; 66: S183-S188.

23. McElhinney DB, Rajasinghe HA, Mora BN, Reddy VM, Silverman $\mathrm{NH}$, Hanley FL. Reinterventions after repair of common arterial trunk in neonates and young infants. J Am Coll Cardiol 2000; 35: 1317 1322.

24. Brown JW, Ruzmetov M, Okada Y, Vijay P, Turrentine MW. Truncus arteriosus repair: Outcomes, risk factors, re-operation and management. Eur J Cardiothorac Surg 2001; 20: 221-227.

25. Kalavrouziotis G, Purohit M, Ciotti G, Corno AF, Pozzi M. Truncus arteriosus communis: Early and midterm results of early primary repair. Ann Thorac Surg 2006; 82: 2200-2206.

26. Morris K, Beghetti M, Petros A, Adatia I, Bohn D. Comparison of hyperventilation and inhaled nitric oxide for pulmonary hypertension after repair of congenital heart disease. Crit Care Med 2000; 28: 2974-2978.

27. Gatzoulis MA, Balaji S, Webber SA, Siu SC, Hokanson JS, Poile C, et al. Risk factors for arrhythmia and sudden cardiac death late after repair of tetralogy of Fallot: A multicentre study. Lancet 2000; 356: 975-981.

28. Fogelman R, Nykanen D, Smallhorn JF, McCrindle BW, Freedom RM, Benson LN. Endovascular stents in the pulmonary circulation: Clinical impact on management and medium-term follow-up. Circulation 1995; 92: 881-885.

29. Kazui T, Osada H, Fujita H; Japanese Association for Thoracic Surgery Committee for Scientific Affairs. Thoracic and cardiovascular surgery in Japan during 2004. Jpn J Thorac Cardiovasc Surg 2006; 54: $363-385$.

30. Koh M, Yagihara T, Uemura H, Kagisaki K, Hagino I, Ishizaka T, et al. Long-term outcome of right ventricular outflow tract reconstruction using a handmade tri-leaflet conduit. Eur J Cardiothorac Surg 2005; 27: 807-814.

31. Isomatsu Y, Shin'oka T, Aoki M, Terada M, Takeuchi T, Hoshino S, et al. Establishing right ventricle-pulmonary artery continuity by autologous tissue: An alternative approach for prosthetic conduit repair. Ann Thorac Surg 2004; 78: 173-180.

32. Yaku H, Yagihara T, Kishimoto H, Isobe F, Yamamoto F, Nishigaki $\mathrm{K}$, et al. Total repair for truncus arteriosus. Nippon Kyobu Geka Gakkai Zasshi 1992; 40: 1182-1188. 